\title{
Long Term Glaucoma Therapy Trend in India
}

\author{
Dr. Sonalee Mittal ${ }^{*}$, Dr. Dinesh Mittal
}

Drishti The Vision Eye Hospital Vijaynagar, DF 63, Sceme No 74c, Opp OM Gurudev Complex, Vijay Nagar, Indore, Madhya Pradesh, India

DOI: $10.36347 /$ sjams.2021.v09i01.006 $\quad$ | Received: 18.12.2020 | Accepted: 31.12 .2020 | Published: 05.01 .2021

*Corresponding author: Dr. Sonalee Mittal

Purpose: To determine the long term Glaucoma Therapy Trend in India. Materials and Methods: A total of two hundred glaucoma patients containing One hundred glaucoma patients from January 2016 - January 2018 time interval and One hundred glaucoma patients from Feburary 2018 - January 2020 time interval on medical therapy were selected. A retrospective analysis regarding monthly income, cost and name of glaucoma medications prescribed, systemic or local side effects was done. Results: Ophthalmologists usually start treatment with Topical Prostaglandin Analogue Travoprost and $\beta$-Blocker Timolol combination. Now they rely less on use of single drug Timolol. This start of treatment with two drugs give the added advantage that even if the patient does not come for routine checkup , combination therapy will take care. Conclusions: Medical therapy for glaucoma is an economic burden to many patients and should be individualized, according to the socioeconomic status and stage of severity of glaucoma.

Keywords: Chronic Glaucoma, Trend in Medical Management.

Copyright (C) 2021 The Author(s): This is an open-access article distributed under the terms of the Creative Commons Attribution 4.0 International License (CC BY-NC 4.0) which permits unrestricted use, distribution, and reproduction in any medium for non-commercial use provided the original author and source are credited.

\section{INTRODUCTION}

Glaucoma is a chronic disease for which lifelong control of intraocular pressure (IOP) is mandatory. The primary treatment for glaucoma is medical, as surgeries have a risk of failure and complications $[1,2]$. Medicines are thought to be safer, however, patients often need $>1$ medication to reach the "target" IOP, which may increase the possibility of side effects, as well as long term costs [3, 4]. With the introduction of innovative tools for early diagnosis and newer medications for treatment, decision-making in diagnosis and treatment of glaucoma has become less complex. The philosophy of glaucoma management is to preserve the visual function and quality of life (QOL) of the individual. Primary Open Angle Glaucoma is a chronic optic neuropathy with characteristic changes in the optic disc and corresponding typical defects in the visual field for which IOP is the only treatable risk factor. The Early Manifest Glaucoma Trial (EMGT) indicated that each $1 \mathrm{mmHg}$ reduction in IOP was associated with a $10 \%$ reduction in the risk of glaucoma progression.

Medications for treatment of glaucoma are Prostaglandin Analogues (increase outflow) Latanoprost, Bimatoprost, Travoprost, Tafluprost, BetaBlockers (decrease inflow) Nonselective Blocker Timolol, Levobunolol Selective Blocker Betaxolol, Alpha-Adrenergic Agonists (decrease inflow)
Brimonidine, Carbonic Anhydrase Inhibitors (decrease inflow) Dorzolamide, Brinzolamide, Miotics (increase outflow) Pilocarpine.

Prostaglandin Analogues decrease the IOP by increasing the Uveo-Scleral outflow of aqueous. $\beta$ Blocker lower IOP by reducing the aqueous secretion due to their effect on $\beta_{2}$ receptors in the ciliary processes and $\alpha_{2}$ Agonist lowers IOP by decreasing aqueous production via an effect on ciliary epithelium and also by increasing uveo-scleral outflow. Dorzolamide or Brinzolamide are topical Carbonic Anhydrase Inhibitors and they lower IOP by decreasing aqueous production by altering ion transport along the ciliary process epithelium. Pilocarpine contracts longitudinal muscle of ciliary body and opens spaces in trabecular meshwork, thereby mechanically increasing aqueous outflow.

Topical Prostaglandin Analogue side effects include conjunctival hyperaemia, foreign body sensation and increased pigmentation of the iris. $\beta$ Blocker side effects are bronchoconstriction, bradycardia, heart block, Exacerbation of Congestive heart Failure and Depression. Pilocarpine side effects are Eye ache, Headache and decrease in vision. Brimonidine side effects are Lethargy, Dry mouth and Allergic reaction. Dorzolamide and Brinzolamide side effects are Metallic taste and Eye irritation. 
Currently, Topical Prostaglandins Analogues (PGAs) or $\beta$-Blocker are the first-line medical treatment for glaucoma. The PGAs are more effective than $\beta$ Blocker in lowering IOP and require only once-daily dosages.

The basic principles that we follow in the management of a glaucoma patient are discussed below.

1. Establish a diagnosis

2. Establish a baseline IOP

3. Set a target IOP

4. Initiate therapy and to lower IOP to target

5. Follow-up.

This study was undertaken to evaluate the long term trend of medical therapy for glaucoma. The goal of medical treatment is to obtain 24-hr IOP control with the minimum concentration and number of medications, as well as minimal local and systemic side effects [5-7]. The selection of initial drug depends on the target IOP. The factors to keep in mind while prescribing a drug include: efficacy, compliance, safety, persistence and last, but not the least, affordability. If the drug is costeffective and dosage is convenient, compliance should improve. Introduction of fixed combination drugs has helped improve compliance and cut down the costs. Once initiated, glaucoma therapy is usually lifelong. This involves considerable expense and inconvenience $[8,9]$. Accordingly, before initiating therapy, we must be sure of the diagnosis and reasonably sure that the medication works [10-12].

\section{Materials ANd Methods}

This was a retrospective study conducted at the Drishti The Vision eye Hospital Indore. The study was conducted from January 2016 to February 2020. A total of two hundred glaucoma patients containing One hundred glaucoma patients from January 2016 January 2018 time interval and One hundred glaucoma patients from Feburary 2018 - January 2020 time interval on medical therapy were selected and their data is analyzed and interpreted. The patients had been diagnosed as glaucoma, following Slit Lamp Bio Microscopy, Fundus Examination using +90 D lens, Applanation Tonometry, Gonioscopy, diurnal phasing and Perimetry (Humphrey® Field Analyzer/HFA).

\section{Results}

Of the 200 patients, $15 \%$ (30) were using only $\beta$-Blocker, $30 \%$ (60) were using a Prostaglandin Analogue and Timolol, 17.5\% (35) patients were using Alpha Agonists and Timolol, and 15\% (30) patient was on a Topical Carbonic Anhydrase Inhibitor and Timolol. About 62.5\% (125) patients were using two drugs while $11 \%$ (22) were on three medications and $11.5 \%$ (23) were using >four medications. Patients using Timolol Maleate alone, spent Rs. 100 per month, Prostaglandin Analogs cost Rs. 300 per month, an Alpha Agonist Rs. 200 per month and those using carbonic anhydrase inhibitors spent Rs.300 per month. The average expenditure in group using multiple medication is 700 Rs per month.

\begin{tabular}{|c|c|c|c|c|c|c|}
\hline \multicolumn{7}{|c|}{ Use of Anti Glaucoma Medication } \\
\hline & Timolol & Travoprost + Timolol & Brimonidin + Timolol & Dorzolamide + Timolol & $\begin{array}{l}\text { Travoprost+ } \\
\text { Brimonidin+ } \\
\text { Timolol }\end{array}$ & $\begin{array}{l}\text { Travoprost+ } \\
\text { Brimonidin+ } \\
\text { Timolol }+ \\
\text { Dorzolamide }\end{array}$ \\
\hline $2016-2018$ & 25 & 30 & 20 & 5 & 12 & 8 \\
\hline $2018-2020$ & 5 & 30 & 15 & 25 & 10 & 15 \\
\hline
\end{tabular}

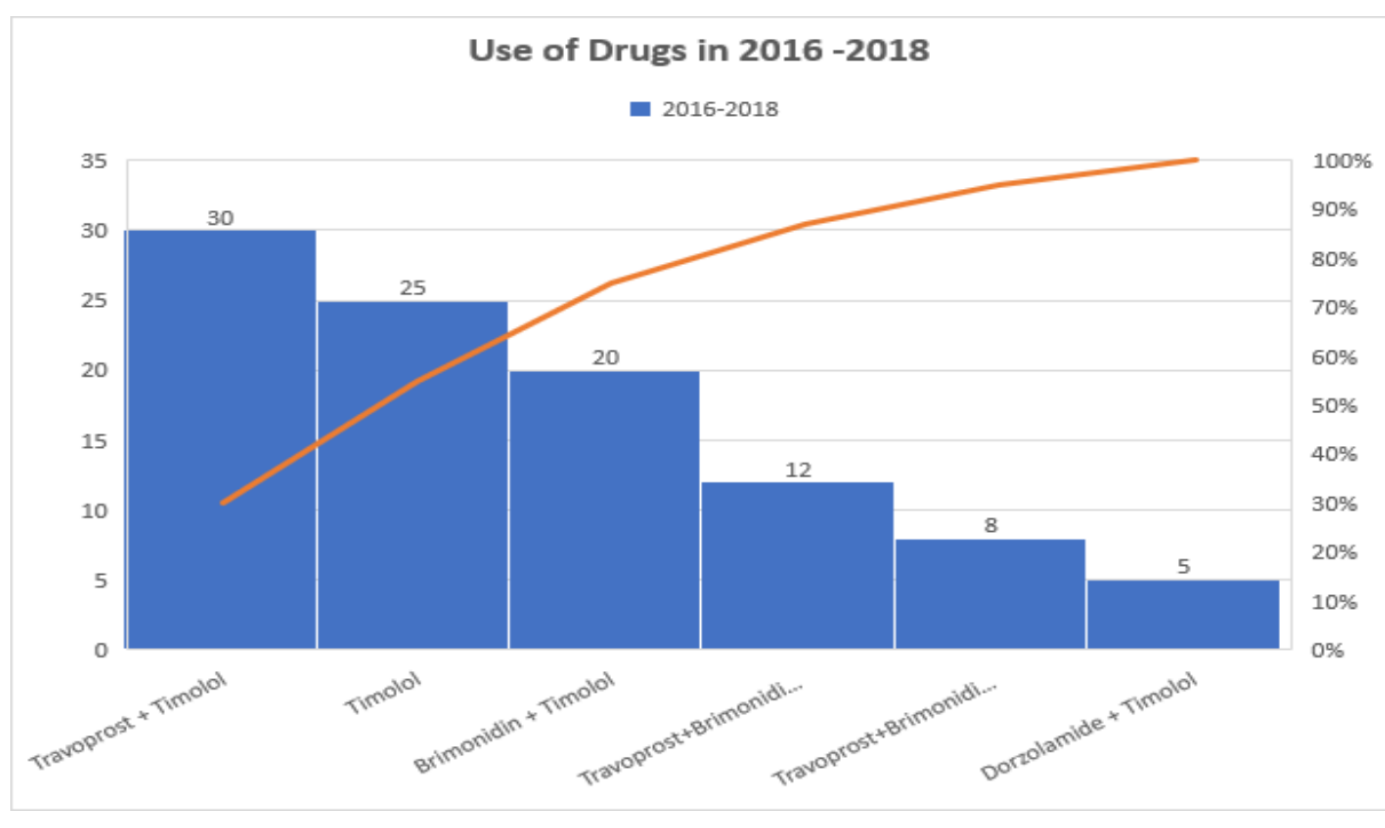




\section{Use Of Drugs}
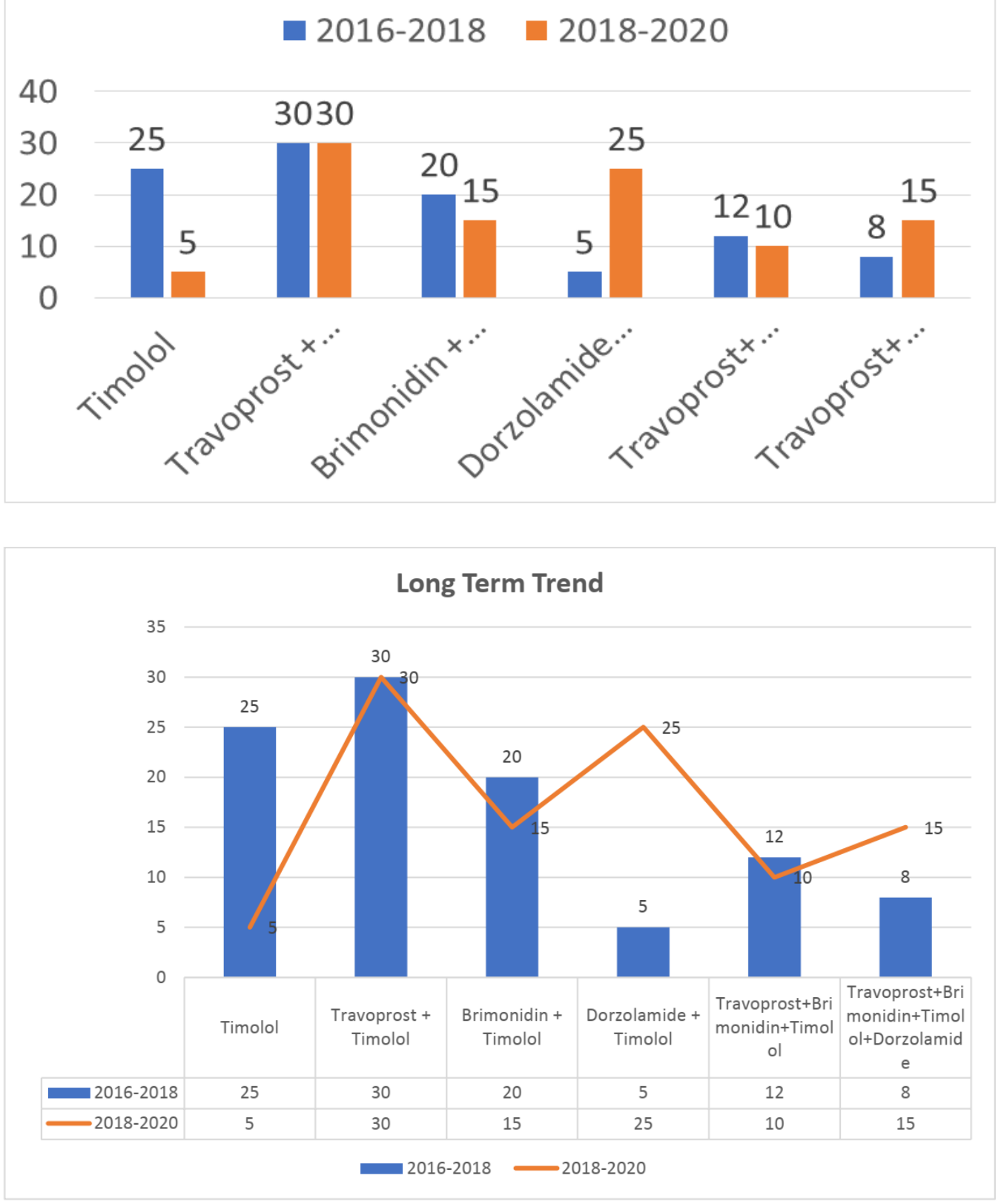

We recommend 3 monthly IOP check and 6 monthly visual fields for patients with moderate to severe glaucoma.

\section{DISCUSSION}

A single medication was being used by $15 \%$ of patients. The average expenditure on $\beta$-Blocker was 4 times less, than Prostaglandin Analogues in a month. Though Prostaglandin Analogues are more effective in their IOP lowering effect than other medications, however, their cost along with local ocular side effects is an issue [13]. Timolol may be started as an initial treatment in poorer patients, when not contraindicated, as it is extremely cost effective and Prostaglandin Analogues may be reserved as an alternative or as add on therapy for patients not achieving "target" IOP with Timolol. However, Prostaglandin Analogue cost is reported to be offset by fewer clinic visits for check up, and by avoiding surgery or costs associated with managing low vision. Pilocarpine which is a cheap, effective and comfortable alternative, should be utilized especially in cases of Angle Closure Glaucoma. As most patients were on more than one drug, drug combinations may be considered, both from an economic and quality of life aspect, after evaluating the efficacy of each component. Only $2.7 \%$ of our patients on Timolol reported systemic side effects in the form of exacerbation of Asthma [3]. Sood et al., from India had described the incidence of systemic adverse effect from timolol to be $11.2 \%$ few decades earlier [6]. This 
Sonalee Mittal \& Dinesh Mittal; Sch J App Med Sci, Jan, 2021; 9(1): 33-37

decline incidence of side effects could be because of Punctal Occlusion being performed by the patients and reflects awareness among doctors of such side effects, and effective history taking prior to starting this drug. Waldock et al., described decrease in pulmonary function test on spirometry in $15 \%$ of patients using timolol after excluding chronic obstructive pulmonary disease patients [3]. Local ocular side effects were encountered by $21.3 \%$ of patients. Local ocular adverse effects were most commonly appreciated with the use of Prostaglandin Analogues (17\%), followed by Alpha Agonists (12\%).

\section{Conclusion}

Topical $\beta$-blockers transformed the landscape of glaucoma management, offering patients a welltolerated topical therapy that is effective in lowering IOP. In most treatment algorithms $\beta$-blockers are considered second-line treatment after Prostaglandin Analogues. Their use is primarily limited by systemic side effects affecting the cardiovascular and pulmonary systems, Brimonidine remains an important tool in IOP reduction, generally as an adjunctive therapy rather than first-line treatment. Topical CAIs provide a welltolerated adjunctive therapy in IOP-lowering and may have a better effect on 24-h IOP-lowering when compared to other drugs. PGAs provide excellent IOP reduction throughout a 24-hour period as well as a low incidence of local side effects and no systemic side effects. This profile has made them the first line for medical management of glaucoma in the majority of patients. If one drug is not effective, then a combination of two drugs - one drug which decreases aqueous production (Timolol or other $\beta$-Blocker, or Dorzolamide) and another drug which increase aqueous outflow (Latanoprost or Brimonidine or Pilocarpine) may be used. In an ideal world (not considering cost), we would like to use a prostaglandin analogue in most glaucoma patients as a first line. Monotherapy aimed at lowering the IOP can usually achieve up to a $35 \%$ reduction in IOP. Combination therapy with multiple drugs may achieve up to a $50 \%$ reduction of IOP. Cost is, however, a consideration and if our target IOP is around $20 \%$ IOP reduction from the baseline, betablockers could be the first line of drug. If our target is $30-35 \%$ IOP reduction from the baseline, Prostaglandin analogues (PGA) like Latanoprost (0.005\%), Bimatoprost $(0.03 \%)$ or Travoprost $(0.004 \%)$ are preferable. If $30 \%$ or more IOP lowering is required and either a Topical Prostaglandin Analogue does not achieve this or there is a cost problem, combination of $\beta$-Blocker with $\alpha-2$ agonists like Brimonidine P $0.15 \%$ or topical carbonic anhydrase inhibitors may suffice. The ocular hypertension treatment study and the collaborative initial glaucoma treatment study have reported that about $50-75 \%$ of patients will need combination therapy at any stage of the disease and may require two or more drugs to reach their target pressure. In such cases, a fixed combination rather than separate drugs has a number of potential advantages including no risk of drug washout, reduced exposures to preservatives with reduced side effects, reduced costs of treatment, and ultimately better patient compliance and quality of life. The socioeconomic impact of medical therapy in glaucoma is considerable, and treatment should be individualized to suit the educational and socioeconomic aspect of each patient. Appropriate patient counseling and holding glaucoma education programs may help in ensuring good patient compliance. Periodic training of ophthalmologists at district hospitals in the management and follow- up of these patients, and using teleophthalmology facilities in peripheral areas would minimize travel issue for such patients.

As more evidence is accumulating Ophthalmologists usually start treatment with Travoprost and Timolol combination. Now they rely less on use of single drug Timolol. This start of treatment with two drugs give the added advantage that even if the patient does not come for routine checkup, combination therapy will take care. Carbonic anhydrase Inhibitors are used more frequently and they are added in treatment regimen earlier as there cost has come down and they decrease the Intra ocular pressure dramatically.

\section{REFERENCES}

1. Akafo SK, Goulstine DB, Rosenthal AR. post trabeculectomy intraocular pressures. Acta Ophthalmol (Copenh). 1992; 70:312-6.

2. Nouri Mahdavi K, Brigatti L, Weitzman M, Caprioli J. Outcomes of trabeculectomy for primary open angle glaucoma. Ophthalmology. $1995 ; 102: 1760-9$.

3. Waldock A, Snape J, Graham CM. Effects of glaucoma medications on the cardiorespiratory and intraocular pressure status of newly diagnosed glaucoma patients. $\mathrm{Br} \mathrm{J}$ Ophthalmol. 2000; 84:710-3.

4. Friedman DS, Hahn SR, Gelb L, Tan J, Shah SN, Kim EE, Zimmerman TJ, Quigley HA. Doctorpatient communication, health-related beliefs, and adherence in glaucoma: results from the glaucoma adherence and persistency study. Ophthalmology. 2008 Aug 1;115(8):1320-7.

5. Delaney YM, Salmon JF, Mossa F, Gee B, Beehne K, Powell S. Periorbital dermatitis as a side effect of topical dorzolamide. Br J Ophthalmol. 2002; 86:378-80.

6. Sood NN, Kumar H, Patil ND, Aggarwal AC, Sihota R. Medical and socio economic aspects of long term therapy of open angle glaucoma. Indian J Ophthalmol. 1991; 39:91-3.

7. Thomas R, Sekhar GC, Kumar RS. Glaucoma management in developing countries: Medical, laser, and surgical options for glaucoma management in countries with limited resources. Curr Opin Ophthalmol. 2004; 15:127-31. 
8. Anand A, Negi S, Khokhar S, Kumar H, Gupta SK, Murthy GV, Sharma TK. Role of early trabeculectomy in primary open-angle glaucoma in the developing world. Eye. 2007 Jan;21(1):405 .

9. Ng WS, Agarwal PK, Sidiki S, McKay L, Townend J, Azuara Blanco A. The effect of socio economic deprivation on severity of glaucoma at presentation. Br J Ophthalmol. 2010; 94:85-7.

10. Rouland JF, Berdeaux G, Lafuma A. The economic burden of glaucoma and ocular hypertension: Implications for patient management: A review. Drugs Aging. 2005; $22: 315-21$
11. Poulsen PB, Buchholz P, Walt JG. Cost analysis of glaucoma related blindness in Europe. Int Congr Ser. 2005; 1282:262-6.

12. Rein DB, Zhang P, Wirth KE, Lee PP, Hoerger TJ, McCall N, Klein R, Tielsch JM, Vijan S, Saaddine J. The economic burden of major adult visual disorders in the United States. Archives of ophthalmology. 2006 Dec 1;124(12):1754-60.

13. Lachaine J, Hodge WG, Steffensen I, Murray C, Barnes D, Foerster V, Ducruet T, Mensinkai S. Prostaglandin analogues for ophthalmic use: a cost-effectiveness analysis. Canadian Journal of ophthalmology. 2008 Feb 1;43(1):33-41. 